\title{
Incorporation of sewage sludge in clay brick and its characterization
}

\begin{abstract}
This study reports the use of sewage sludge generated from sewage treatment plant (STP) as raw material in a clay brick-making process. The physico-chemical and mineralogical characterization of the sewage sludge and clay were carried out in order to identify the major technological constraints and to define the sludge pretreatment requirements if necessary. Moreover, the effects on processing conditions and/or on changes of typical final characteristics are also evaluated. Bricks were produced with sewage sludge additions ranging from 10 to $40 \%$ by dry weight. The texture and finishing of the surface of sludgeamended clay bricks were rather poor. As for the physical and chemical properties, bricks with a sludge content of up to $40 \mathrm{wt} . \%$ were capable of meeting the relevant technical standards. However, bricks with more than $30 \mathrm{wt} . \%$ sludge addition are not recommended for use since they are brittle and easily broken even when handled gently. A tendency for a general degradation of brick properties with sludge additions was observed due to its refractory nature. Therefore, sludge bricks of this nature are only suitable for use as common bricks, which are normally not exposed to view, because of poor surface finishing.
\end{abstract}

Keyword: Sewage sludge; Utilization; Clay brick production; Physico-chemical; Mineralogical characterization; Wmr 690-4 